\title{
Principios constitucionales, generales y procesales en tiempos de víctimas y justicia transicional
}

\author{
Constitutional, general and procedural principles in times of victims and transitional \\ justice
}

\author{
DANiela SÁNCHEz GutiérRez ${ }^{*}$ \\ JAiro Vladimir Llano FranCO ${ }^{* *}$
}

* Egresada de Derecho de la Universidad Libre de Colombia Seccional Cali, joven investigadora.

** Ph. D. en Derecho por la Universidad Externado de Colombia, Becario del Instituto Internacional de Sociología Jurídica de Oñati, Antropólogo y Especialista en Antropología Jurídica por la Universidad del Cauca. Profesor e investigador de la Universidad Libre Seccional Cali.

Fecha de recepción: 28 agosto de 2019 Fecha de aprobación: 30 de Noviembre de 2019

Para citar este artículo / To reference this article Llano, J. Sánchez, D (2019) Principios constitucionales, generales y procesales en tiempos de víctimas y justicia transicional. Inciso, 21(2) ; 229- 241

\section{Resumen}

Desde los años 90 del siglo pasado las negociaciones entre los grupos insurgentes y el gobierno central en el contexto colombiano han sido una constante, llevando a cabo de forma paulatina una manera de aplicar el derecho que se escapa a los postulados formalistas y positivistas que han predominado por varias décadas la práctica jurídica, esta nueva forma sí se puede decir, de aplicar el derecho se ha dado por la influencia tanto del derecho constitucional contemporáneo como por las transformaciones del derecho internacional, particularmente lo relacionado con los Derechos Humanos, configurando otra concepción de justicia donde lo importante no es el castigo, sino la reparación en distintos aspectos y la convivencia de los ciudadanos, como es el caso de la justicia transicional, por eso los principios adquieren un protagonismo inusitado por su amplitud y la posibilidad de resolver múltiples problemas jurídicos como los provenientes de los conflictos armados internos como el colombiano y la posibilidad que una práctica de confrontación de paso a acciones de convivencia e inclusión de los ciudadanos. Este artículo se desarrolló mediante la hermenéutica jurídica analizando jurisprudencia de la Corte Constitucional, leyes, tratados 
internacionales y conceptos de expertos en justicia transicional. Así pues, se evidenció que en el caso de Colombia en el proceso de reparación integral prevalece la reconstrucción de la memoria y la verdad así como la no repetición, sobre los demás componentes de dicha reparación que garanticen el cumplimiento de los acuerdos de paz desde la óptica de los principios procesales establecidos por el DIDH.

Palabras clave: Conflicto armado, derechos humanos, estado, justicia social, restauración.

\section{Abstract}

from the 90s to the last century the relations between the insurgent groups and the central government in the Colombian context has been a constant, a form of applying the right of escape to the formalist postulates has been carried out in a cape. and positivists who have predominated for the same reason, on the contrary. where the important thing is not the punishment but the reparation in different aspects and the coexistence of the citizens, as in the case of transitional justice, in which the principles acquire an unusual protagonism for their amplitude and the possibility of solving multiple legal problems such as the internal armed conflicts, and the possibility of a confrontational practice of passing actions of coexistence and inclusion of citizens.

Keywords: Law, Justice, Social Justice, Violation of human rights,, Victim, Restoration, State, Positivism, armed conflict.

\section{Introducción}

En las últimas décadas la transformación del derecho ha sido determinante para adecuarse a los desafíos que se originan por fenómenos como la globalización, las tensiones sociales, los conflictos, las nuevas tecnologías, entre otras situaciones, precisamente, entre las transformaciones que han surgido en el derecho y la ciencia jurídica se encuentra la central importancia de los principios constitucionales y del derecho con los cuales se pretenden resolver los problemas jurídicos en sus diferentes niveles, entre ellos los de mayor complejidad, por eso en lo contemporáneo, los principios constitucionales se han convertido en referentes obligados tanto para el derecho formal como para procedimientos informales, como lo que ocurre con la compensación para las víctimas del conflicto armado y la nueva propuesta de justicia para la paz que se está implementando en el país.

El artículo referencia los conceptos de los principios generales del derecho procesal en la reparación de daños de víctimas en Colombia como medida restaurativa. Las pretensiones son analizar en sentido amplio y restringido los principios generales del derecho procesal ordinario en el ámbito de una jurisdicción especial y las diversas formas de reparación de daños a víctimas dentro de un sistema restaurativo. La metodología que se utilizó fue la hermenéutica jurídica, ya que se interpretó la jurisprudencia de la Corte Constitucional, leyes y tratados internacionales de Derechos Humanos que se relacionaron con los teóricos del derecho cuyos postulados son el reconocimiento de principios constitucionales e internacionales del derecho, complementándose la parte conceptual con analistas y expertos en justicia transicional.

El sentido clásico de los principios generales del derecho procesal ordinario son restringidos, ambiguos en comparación con la nueva noción de principios orientadores de la ruta de reparación integral que pretende proteger los derechos irrenunciables de las víctimas, por cuanto 
su desarrollo va orientado a prevalecer a esta última y no por el contrario, en una distribución equitativa de las partes en la acción jurisdiccional como sucede en la justicia ordinaria donde las partes son privilegiadas con la carga dinámica de la prueba, la igualdad entre las partes, entre otros.

Es por ello que se propone la siguiente hipótesis: la reparación del daño sufrido por la víctima en un sistema restaurativo de justicia debe ser entendido bajo el concepto universal del principio de progresividad de los principios fundamentales del derecho procesal. Lo anterior, es una reflexión para examinar la reparación de daños desde una óptica progresista del derecho internacional humanitario. La observancia de estos nuevos principios es fundamental a la hora de reparar el daño y regresar las cosas a su estado anterior como superación del estado de cosas inconstitucionales en Colombia.

La primera parte del artículo titulada: "Hacia una definición de los principios constitucionales, generales y procesales", muestra la importancia de los principios en el derecho contemporáneo en sus diferentes áreas para resolver los problemas jurídicos que se presentan en los Estados y las múltiples sociedades, para sustentar este protagonismo de los principios, se acudió a teóricos como Dworkin y Alexy, entre otros que refuerzan esta concepción. En la segunda parte titulada: "Principios constitucionales y procesales, víctimas del conflicto y justicia transicional", se sustenta el papel de los principios constitucionales en las nuevas formas de concebir el derecho y la práctica jurídica, ya que la jurisdicción ordinaría no es suficiente para dar por terminados conflictos armados y resarcir a las víctimas, por eso la justicia transicional se convierte en la posibilidad de llevar a la culminación real de las confrontaciones armadas y la apertura a la convivencia no solamente de las actores enfrentadas sino de la sociedad en general. En la parte final titulada: "Principios y protección de las víctimas en el posconflicto", se presentan las concepciones teóricas, jurisprudenciales e internacionales sobre la situación colombiana en lo más reciente, como es la aplicación de ese derecho transicional y constitucional de principios en la realidad conflictiva y pos conflictiva del país.

\section{Hacia una definición de los principios constitucionales, generales y procesales}

Las transformaciones recientes en el derecho han determinado el protagonismo de los principios para resolver problemas jurídicos, incidencia que se ha trasladado a especialidades como el derecho procesal, precisamente, uno de los referentes teóricos de los principios:

Llamo principio a un estándar que ha de ser observado, no porque favorezca o asegure una situación económica, política o social que se considera deseable, sino porque es una exigencia de la justicia, la equidad o alguna otra dimensión de la moralidad [...] Un principio enuncia un objetivo social (nadie se beneficia de su propia injusticia), o si se interpreta que una directriz enuncia un principio (esto es, el principio de que el objetivo que defiende la directriz es valioso) o si se adopta la tesis utilitarista de que los principios de justicia enuncian encubiertamente objetivos (asegurar la mayor felicidad para el mayor número). (Dworkin, 2002, pp. 72-73)

Con el avance y transformaciones del derecho, los principios no se han limitado solamente a lo constitucional, sino que se han expandido en las distintas áreas jurídicas, entre las cuales se incorpora hasta el derecho internacional, de esta forma lo interpreta Calvo (2014), para el caso específico de la progresividad lo demuestra: "[...], el principio de progresividad que tiene sustento en el Derecho Internacional de los Derechos Humanos, ya que este contempla la obligación de los Estados Partes de lograr el desarrollo progresivo de los derechos económicos, sociales y culturales". (p. 159) 
Pero los principios como el de progresividad que se encuentra relacionado con la justicia transicional, no se ha limitado a los debates teóricos, en la práctica jurídica ha sido esencial, como lo muestra la jurisprudencia de la Corte Constitucional, que en sentencia C-443 de 2009 plasma el concepto de principio de progresividad en el ordenamiento interno:

[...] la obligación de los Estado en no retroceder en los niveles alcanzados de protección". Así mismo Calvo (2014), asegura que dicho principio es esencial para el Estado social de derecho “.... implica [...] el de progreso, consistente en la obligación estatal de mejorar las condiciones de goce y ejercicio de los derechos económicos, sociales y culturales [...] el concepto de realización progresiva constituye un reconocimiento del hecho de que la plena realización de los derechos [...] generalmente no podrán lograrse en un corto periodo de tiempo. (p.146)

Los Estados contemporáneos que se soportan constitucionalmente en los principios y los derechos, no podrán retroceder en los avances alcanzados en la protección y garantía de estos principios. Desde esta perspectiva la noción de principios generales del derecho es esencial para su vinculación sustancial y consolidación de los específicos principios fundamentales del derecho procesal tanto en la justicia ordinaria como en la especial.

La noción de principio no es unánime frente al origen y fin que este persigue, una de las teorías más reconocidas y respaldadas para la transformación de los principios por encima de los preceptos legales y las reglas de derecho, es precisamente la teoría de la argumentación jurídica, quien propone la importancia y superioridad de los principios:

[...], los principios son normas que ordenan que se realice algo en la mayor medida posible, en relación con las posibilidades jurídicas y fácticas. Los principios son, por consiguiente, mandatos de optimización que se caracterizan por que pueden ser cumplidos en diversos grados y por la medida ordenada de su cumplimiento no solo depende de las posibilidades fácticas, sino también de las posibilidades jurídicas. (Alexy, 2002, pp.13-14)

A este tipo de teoría y concepción se le contrapone las corrientes positivista y neopositivista del derecho, que se empeñan en construir desde una metodología científica el estudio del derecho. Para los positivistas los principios son identificados solo en la medida en que la ley les da existencia y obligatoriedad en el ordenamiento jurídico; su razón de ser se materializa a través de la norma positiva:

Las teorías conceptuales del derecho como el positivismo están principalmente enfocadas en dar una explicación global de los criterios de validez. En primer lugar, los criterios distinguen las normas que cuentan como derecho de las normas que no tienen este estatus. En segundo lugar, los criterios describen las propiedades que explican por qué las normas jurídicas tienen el estatus de derecho: tales normas tienen este estatus porque instancian aquellas propiedades. Dicho de otra forma, la instanciación de estas propiedades convierte en una norma jurídicamente válida en una sociedad a cualquier norma que las tenga. (Himma, 2011, pp.15-16)

Aunque el positivismo jurídico no desconoce la importancia de los principios en la interpretación que se deba hacer de la ley, por ejemplo, el principio de legalidad, se limita al afirmar que estos se derivan de la norma, cuando ha sido precisamente el derecho positivo quien ha tenido que recoger estos postulados para no estar por fuera de las transformaciones del derecho y las deliberaciones contemporáneas, uno de los representantes destacados de estas transformaciones es Hebert Hart, precisamente, Chiassoni lo cita para exponer la transformación del positivismo jurídico: 
En algunos escritos publicados entre 1958 y 1967, Hebert Hart desarrolla un análisis de los usos del positivismo jurídico [...] la efectiva existencia de un sistema jurídico, por cuanto opresivo e injusto, ofrece a una gran cantidad de seres humanos un mínimo de paz [...] estos son valores que ningún individuo está moralmente justificado para poner en peligro oponiendo resistencia al derecho. (Chiassoni, 2016, pp.69-70)

La ley al regular conductas se preocupa por delimitar la circunstancia fáctica y su consecuencia jurídica que puede oscilar entre el castigo y la compensación, desconociéndose que la norma jurídica al no predecir en su totalidad la conducta humana origina vacíos que al no resolverse desde idearios y principios como justicia, equidad y paz podrían ocasionary reproducir situaciones conflictivas: "Llamo principio al patrón que debe ser observado, no porque promoverá o asegurará una situación económica, política o social considerada deseable, sino porque es una exigencia de justicia o equidad o de alguna otra dimensión de la moralidad" (Dworkin, 1997, p. 19).

Lo que Dworkin Ilama la moralidad del derecho al referirse a los principios, se puede considerar como la incidencia de la política en el derecho al considerar que la norma jurídica al tener una carga sociopolítica puede inclinarse a favorecer ciertos sectores sociales. Situación que se aprecia en las leyes que han beneficiado la propiedad privada o el derecho del acreedor en contraposición al deudor:

[...], la evolución del Derecho a través de la historia significa una limitación cada vez mayor de la propiedad privada [...] la actividad libre y el ejercicio de la fuerza productiva de cada uno , afirma Lassalle, son todavía propiedad privada exclusiva del propietario de la materia prima y del capital que, por lo mismo, obstaculiza la libertad de hecho del trabajador. (Treves, 1988, p.67)

La propuesta del profesor Alexy de la ponderación es esencial para comprender cómo los principios son incorporados al ordenamiento jurídico estatal o internacional. Esta vinculación se realiza por medio de casos concretos donde dos o más principios colisionan, situación que es resuelta desde la ponderación que realiza el juez:

La ponderación es entonces la actividad consistente en sopesar dos principios que entran en colisión en un caso concreto para determinar cuál de ellos tiene un peso mayor en las circunstancias específicas, y, por tanto, cuál de ellos determina la solución para el caso. (Bernal, 2008, p. 97)

Al colisionar sobre un caso concreto el principio que se determina como perdedor no desaparece del ordenamiento jurídico, se mantiene hasta que sea involucrado en otro caso donde resulte más afectado y requiera de mayor protección por parte del juez en su decisión, por eso la acción de la ponderación no suprime los principios del ordenamiento, situación que no sucede con las reglas, ya que al colisionar con un principio y este resulta el más afectado la regla debe desaparecer, proceso que se conoce como la inconstitucionalidad de una determinada norma o ley: "Cuanto mayor sea el grado de insatisfacción o de detrimento de un derecho o principio, mayor debe ser la importancia de satisfacer el otro" (Alexy, 2007, p.78).

La ponderación se sustenta, precisamente, en un principio, el de la proporcionalidad con la pretensión de que los jueces lo apliquen en sus decisiones cuando colisionan principios en un caso concreto, la proporcionalidad, brinda los elementos necesarios para que esta decisión sea lo menos subjetiva posible:

Interpretar los derechos constitucionales a la luz del principio de proporcionalidad supone tratar a los derechos constitucionales como exigencias de optimización; esto es, como principios y no 
como reglas. En tanto que exigencias de optimización, los principios son normas que requieren que algo sea realizado en la mayor medida de lo posible, dadas sus posibilidades normativas y fácticas. (Alexy, 2007, p.61)

Los principios generales del derecho procesal, como el debido proceso, tienen su origen en la familia jurídica anglosajona en concordancia con los inicios del Estado de derecho dentro de un marco de Estado democrático que garantice la progresividad de los derechos fundamentales dentro de un proceso jurídico, el primer texto constitucional de la modernidad que referencia el debido proceso es The Bill of Rights de los Estados Unidos, en el cual se indica:

El origen del debido proceso se encuentra en el derecho anglosajón, teniendo en cuenta el desarrollo del principio due process of law [...] en la tradición correspondiente al common law se ha presentado un desarrollo jurisprudencial y doctrinal bien prolijo; tradición en la que deben tenerse en cuenta países que recibieron el influjo del derecho inglés como es el caso de Estados Unidos de América. (Esparza, 1995, pp. 74-76)

Los principios son creadores y orientadores de la norma, son su fundamento filosófico, que se encuentran establecidos en la jurisprudencia constitucional aportando, influenciando e impactando el campo jurídico, con la pretensión de que los casos concretos sean resueltos desde los principios constitucionales, es aquí cuando se determina que estos cumplen una función de interpretación y resolución de los problemas jurídicos.

De igual forma han sido vinculados por las distintas áreas de la ciencia jurídica, como el derecho procesal, precisamente, por la relación de surgimiento de este con los principios. Sin la aplicación de estos en el proceso, se estaría en una situación contradictoria, debido a que los derechos fundamentales que son esenciales para la especialidad del derecho procesal. La Corte Constitucional en sentencia C -284 del 2015 establece el reconocimiento y su función en el ordenamiento jurídico colombiano de la siguiente manera:

En algunos casos se advierte que ellos cumplen una función crítica de los ordenamientos. En este caso los principios actúan como la imagen de un derecho ideal al que deben apuntar los ordenamientos históricos. Otra perspectiva señala que los principios generales actúan como verdaderas normas jurídicas y cumplen por ello una función integradora. Finalmente, una tercera postura advierte que la tarea de los principios consiste en precisar el alcance de las fuentes del derecho, cumpliendo entonces una función interpretativa. (Corte Constitucional, sentencia C $-284 / 2015)$

Si bien cada área del derecho vincula los principios procesales que considera y determina, también se han identificado algunos de estos se aplican indistintamente de la especialidad en relación con la garantía de los derechos fundamentales que a las partes les asiste. Los siguientes principios cumplen con esta característica: (i) de igualdad, (ii) dispositivo, (iii) de legalidad, (iv) de economía procesal, (v) de buena fe y lealtad procesal, (vi) de publicidad, (vii) del derecho a la defensa, (viii) de onerosidad, (ix) de inmediación, (x) de la motivación de las sentencias y (xi) de la carga de la prueba. Estos son anacrónicos, no están acordes con las necesidades de la sociedad actual:

Estos principios se pueden clasificar en básicos, particulares y alternativos. Los primeros son aquellos que resultan comunes a todos los sectores y las ramas del derecho procesal dentro de un ordenamiento jurídico determinados. Tal es el caso del principio de contradicción [...] principio dispositivo, igualdad de las partes, principio de economía procesal. (Ovalle, 2011, pp. 200-2001) 


\section{Principios constitucionales y procesales, víctimas del conflicto y Justicia Transicional}

Estos principios se encuentran en el Código General del Proceso y son referenciados en la jurisdicción ordinaria donde la Corte Constitucional colombiana ha tenido diferentes pronunciamientos, sin embargo, las transformaciones del derecho en los años recientes ha determinado que la justicia ordinaria no es suficiente para resolver ciertos problemas socio jurídicos como lo respectivo a la terminación del conflicto armado en el contexto colombiano, donde el proceso aparece como un derecho más flexible y amplio que pueda comprender situaciones de confrontación entre grupos armados que dejaron víctimas en la población civil e incluso de estos mismos grupos, si se aplicara la jurisdicción ordinaria particularmente la penal, las penas serían restrictivas de las libertades de los implicados por décadas, reproduciendo el conflicto entre los actores armados sin la posibilidad de la negociación y llevando a una multiplicación de las víctimas y los victimarios, por eso los procesos de diálogos y negociación se inscriben en otro tipo de jurisdicción y de justicia especial, lo que constitucional y legalmente se ha reconocido como la Jurisdicción Especial para la Paz, precisamente, con otros tipos de principios más acorde con la nueva propuesta de jurisdicción.

Para reparar el daño a las víctimas es necesario acudir a ciertos principios que los protegen jurídicamente, pero también a otros principios que posibilitan la creación de la estructura jurídica que determina la terminación del conflicto armado entre el Estado y las guerrillas colombianas, que pretende limitar la reproducción de las víctimas por este conflicto que ya superó el medio siglo, precisamente, entre los principios que están desde la estructura se encuentra el principio de progresividad.

Este principio supraconstitucional es de obligatorio cumplimiento porque prohíbe el retroceso legislativo en materia de derechos sociales adquiridos, es decir, los Estados no pueden desconocer derechos alcanzados; por el contrario, deben aumentar progresivamente la satisfacción de los mismos, ya que una postura distinta sería, prima facie, una desprotección de las garantías constitucionales:

Los Estados no pueden quedarse inmóviles ante la satisfacción de los derechos sino que deben propender por el aumento de la cobertura y de las garantías que le son propios, hasta el máximo posible, a través del establecimiento de medidas legislativas y de cualquier otra índole [...] implica la prohibición correlativa de regresividad. (Corte Constitucional, sentencia T-469/13)

El principio de progresividad en el caso de la Ley de víctimas, pretende que mientras esta se implementa no se desvinculen los derechos sociales fundamentales ya reconocidos, sino por el contrario la garantía para las víctimas sean mayores debido a que provienen de una situación compleja donde los derechos fundamentales fueron restringidos, por eso este tipo de leyes lo que pretenden es una compensación de las víctimas, por eso, el principio de reparación dentro de los procesos muestra clara favorabilidad a las víctimas en relación con el victimario.

El principio de igualdad procesal desaparece en la Ley 1448 de 2011 entre víctima y victimario, porque la carga de la prueba no recae sobre la víctima, sino que es el victimario quien decide por voluntad propia si acepta o no ingresar a una Jurisdicción Especial de Paz asumiendo todos las responsabilidades legales y procesales que ellas exigen para que pueda ser beneficiado dentro de un proceso transicional. En el artículo 78 de la ley la inversión de la carga de la prueba exonera a la víctima: “[...], bastará con la prueba sumaria [...] para trasladar la carga de la prueba al demandado o a quienes se opongan a la pretensión de la víctima en el curso del proceso". 
El beneficio es siempre a favor de la reparación integral de la víctima, por lo que se restringen transitoriamente los principios procesales clásicos de un determinado proceso judicial ordinario para dar protección al sujeto principal de esta justicia: la víctima, debido a la vulneración de sus derechos humanos en el conflicto armado; derechos fundamentales de obligatorio cumplimiento y protección constitucional por parte de las instituciones estatales. Al respecto, la Corte Constitucional en sentenciaT-239/13 ha resuelto salvaguardar la condición de desplazado como sujeto de especial protección constitucional debido a su condición de especial vulnerabilidad.

Es por esta razón que los principios procesales clásicos en la justicia transicional colombiana o Ley de víctimas (Ley 1448 de 2011), restringe los principios procesales que están a favor del acusado para ampliar su concepto y su protección a la víctima, quien ingresa ipso facto al proceso con la calidad de víctima y el reconocimiento público por parte del Estado, la sociedad y el victimario.

A esto se denomina restricción del concepto de principios procesales, para denotar que si bien no hay igualdad frente a la carga de la prueba o el derecho constitucional de presunción de inocencia, es porque el modelo transicional busca ahorrar tiempo en investigación de responsabilidades para dedicarlo a reparar integralmente a las víctimas y a la sociedad en general. Si bien hay una restricción en los principios procesales clásicos como lo mencionamos, hay una evolución procesal en reparación integral de víctimas respaldada por el principio de progresividad que marca la Ley 1448 de 2011 en Colombia. Estos han sido desarrollados históricamente para garantizar la eficacia del proceso, es por esta razón, que su alcance es progresista de acuerdo con el margen de protección de los derechos fundamentales que adopta cada país.

Es por esto necesario identificar cuáles son las funciones que cumplen dichos principios a la hora de reparar a las víctimas en un marco de conflicto armado colombiano. Desde la expedición de la Ley 1448 de 2011 o Ley de Víctimas, Colombia ha sido respetuosa del control de convencionalidad que ordena garantías mínimas de verdad, justicia sin impunidad, reparación integral y no repetición de violaciones de derechos humanos. La importancia sustantiva y procesal que ella contiene per se tiene como fundamento esencial la observancia de principios constitucionales internacionales llevados a leyes procesales, como es el caso del capítulo II de la Ley 1448 de 2011 que determina que: "La dignidad humana, la buena fe, la igualdad, garantías del debido proceso, respeto mutuo, progresividad y publicidad" son principios orientadores de la actividad procesal en jurisdicción especial de justicia transicional.

Sin embargo, conviene subrayar que los principios mencionados son propios del derecho civil y de la actuación procesal que han adoptado otras ramas del derecho. Pero como se ha expresado ya no se está frente a un proceso ordinario, ni frente a víctimas de delitos comunes, se está quizás frente uno de los mayores desafíos de la sociedad colombiana: restablecer la paz, consolidar la reconciliación y la convivencia entre los ciudadanos.

En efecto estos principios básicos son importantes, pero reducidos en comparación a la respuesta de paz que se espera de ellos. Hizo bien el legislador en ampliar el abanico de protección constitucional de las víctimas al incluir en la Ley 1448 de 2011 los principios de justicia transicional, carácter de las medidas transicionales, condenas de subsidiaridad, coherencia externa e interna, enfoque diferencial, participación conjunta, obligación de sancionar a los responsables, gradualidad, sostenibilidad, complementariedad, colaboración armónica, aplicación normativa, participación conjunta y medidas especiales de protección. (Capítulo II, Ley 1448 de 2011) 
Los acontecimientos sociojurídicos que surgirían en el proceso de acuerdo entre el gobierno y las guerrillas de las FARC, Ilevarían a mostrar la importancia de los principios constitucionales e internacionales para alcanzar la convivencia entre actores que han sido considerados como enemigos, por eso tanto el acuerdo, los documentos que se desprenden de él, la jurisprudencia de la Corte Constitucional y los pronunciamientos de las instituciones internacionales han sido el soporte para que en el horizonte colombiano la convivencia sea una realidad, así es expuesto por Correa Magdalena (2017) en su libro Justicia Transicional balance y desafío Constitucional:

En el actual proceso de paz, en efecto, no obstante haberse iniciado los diálogos en 2012, fue solo con el comunicado del 17 de julio de 2014 que se estableció el acuerdo sobre los mecanismos de participación directa de las víctimas en la mesa [...] Se destaca también aquí la contribución de la jurisprudencia constitucional en la configuración de la justicia transicional desde arriba. Con ello no se pretende negar su valor esencial para introducir al Estado en la atención de las víctimas del desplazamiento y de las distintas formas de violencia producidas durante el conflicto. Con todo, en respaldo de los peticionarios y de la noción de Constitución garantista, tales providencias del juez constitucional se dictan desde su posición de supremo interprete. (Correa, 2017, p. 45)

Los principios constitucionales se convierten en el complemento para consolidar las propuestas legales de la terminación del conflicto y en especial de las víctimas de las cuales se deben resarcir sus daños que se originaron en un conflicto armado interno donde las instituciones estatales tienen una amplia responsabilidad. En este contexto la propuesta teórica de Alexy (1993) en Teoría de los Derechos Fundamentales, refiriéndose a los fines propios de los principios como mandatos de optimización adquiere una inusitada importancia:

Los principios son normas que ordenan que algo sea realizado en la mayor medida posible, dentro de las posibilidades jurídicas reales existentes. Por lo tanto, los principios son mandatos de optimización que están caracterizados por el hecho de que pueden ser cumplidos en diferente grado y que la medida debida de su cumplimiento no solo depende de las posibilidades reales, sino también de las jurídicas. (Alexy, 1993, pp.86- 87)

En concordancia, se puede ampliar el concepto de principio constitucional al derecho procesal precisando que las garantías del debido proceso cuyo fin es la verdad, la justicia, la reparación y no repetición tienen mayor nivel de cumplimiento entorno a las posibilidades de protección constitucional que impone el legislador al momento de hacer la norma y el operador jurídico a la hora de fallar los casos amparado en los criterios de la sana crítica:

Los derechos humanos son derechos morales. Estos derechos tienen validez solamente en razón de su corrección material. Su institucionalización, positivación o efectividad social no desempeña ningún rol como criterio de validez. Lo característico de estos derechos es su funda-mentalidad, propiedad que alude a la protección y la satisfacción de intereses y necesidades fundamentales. Por este motivo, los derechos humanos constituyen el núcleo delas teorías de la justicia. (Borowski, 2003, pp. 30 - 31)

El conflicto colombiano por ser uno de los más cruentos, donde se han manifestado graves y sistemáticas maneras de violar los derechos humanos, tiene hoy como consecuencia un número amplio de víctimas, más de ocho millones según el Registro Único de Víctimas (RUV). Ahora bien, con ese amplio universo de víctimas a reparar, donde son diversas las maneras en que fueron vulneradas, sumándole a ello, la obligación de reparar violaciones que en la mayoría de los casos son irreparables. Por esto, se ha establecido la necesidad de reparar de una manera justa, eficiente y adecuada para cada caso concreto, a través de programas administrativos que vayan en armonía con los estándares internacionales y ajustándolos al contexto de acuerdo con lo establecido por De Greiff (2009). 
Cabe aclarar que esta reparación a diferencia de la que se hace por vía judicial, tiene un carácter de reparación material y simbólica en los ámbitos individual y colectivo, en contraposición a la reparación que se hace teniendo en cuenta los reclamos individuales y que va en proporción al daño sufrido, o como lo diría Díaz (2010) la reparación no está dirigida a restituir o compensar a las víctimas por cada uno de los daños sufridos, ni en directa proporción al daño. De la misma manera De Greiff (2009) ha manifestado que la justicia en las reparaciones a la hora de resarcir un gran número de casos, debe verse desde una perspectiva distinta a aquella idea de justicia que se ve en un proceso judicial, que se basa en el criterio de reparación en proporción al daño causado.

Por eso, la idea de la reparación integral debe tener en cuenta la complejidad del programa, esto es, que no se debe agotar la reparación a indemnizaciones administrativas, ya que sería tener una mirada mercantilista de la situación y reduccionista en términos humanos, ya que si bien es cierto las compensaciones en términos monetarias son necesarias para aquellas personas que han perdido vivienda y tierras; es necesario además que se comprendan otras medidas que busquen la satisfacción a la hora de reconocer la dignidad de las víctimas, y esto se hace a través de honrar la memoria de las víctimas, reconstruir la verdad, la memoria histórica, de rehabilitar física, psíquica y psicosocialmente. Igualmente, se debe garantizar que las situaciones por las que tuvieron que pasar no se volverán a repetir, apreciación que estaría acorde con los fines de la justicia transicional, como lo expone Bernal (2018) en su artículo "La aporía de la justicia transicional y el dilema constitucional del Marco Jurídico para la Paz":

Los principales fines de la justicia transicional son asegurar la atribución de responsabilidad derivada de las violaciones a los derechos humanos, la revelación de la verdad, la compensación de las víctimas, la desmovilización de individuos y grupos que participan en el conflicto social, la reconciliación entre los oponentes, el fin de un régimen autoritario o de un conflicto armado interno, y la configuración de un acuerdo democrático e inclusivo que conduzca a la expedición de una nueva Constitución permanente. (Bernal, 2018, p. 307)

Ahora bien, en el periodo de transición que se está dando en el país, lo que buscan las medidas de reparación acordadas entre FARC - EP y Estado colombiano, es que se dé la reconciliación y convivencia de las comunidades, que no es otra cosa que la constitución de una nueva comunidad política. En ese orden es evidente que en el marco del proceso de transición hacia la paz, como el que vive Colombia, el derecho a reparar adquiere una connotación especial. La reparación en un contexto como el colombiano debe también incluir las situaciones de injusticia y opresión de comunidades de donde provienen las víctimas y a las cuales no se les garantizaron derechos fundamentales para su subsistencia y reproducción cultural, al lograr que estas comunidades sean vinculadas al proceso transicional y minimicen las causas que llevaron a la aparición de los actores del conflicto armado y sus víctimas, se estaría asistiendo a un real desmonte de las situaciones que reproducían los distintos actores armados del conflicto:

Es prudente recordar que los elementos de derechos de las víctimas -justicia, verdad, reparación y garantías de no repetición- tienen unas finalidades prácticas [...] no solo han sido vulneradas sus circunstancias por el conflicto, sino también por las desigualdades y discriminaciones históricas que se han mantenido en parte por la ausencia de una adecuada intervención estatal. (Llano, 2018, p. 212).

En este orden y dirección, De Greiff (2009) propone pensar la reparación de tal manera que no solo debe ser justa, sino también adecuada, atendiendo la situación particular de cada víctima, es decir, teniendo en cuenta sus necesidades especiales y proporcionarse de manera efectiva. 
Asimismo, lo que se busca con la reparación integral es que se reconozca a las víctimas y los perjuicios a los que estas fueron sometidas. De igual manera, que se indague sobre cuáles son las medidas de reparación idóneas para cada caso concreto, con el fin de restablecer la dignidad de las víctimas como ciudadanos y contribuir de esta manera a la convivencia y la reconciliación en las comunidades.

Precisamente, en los procesos de transición como ocurre con el caso colombiano se pretende la garantía de los derechos de las víctimas a cambio de no llevar a cabo la aplicación del derecho penal ordinario de los responsables, sino su incorporación a la vida social y política del país, debido a sus aportes para que los derechos sean realizados plenamente, para que estas pretensiones no tengan inconvenientes de tipo jurídico, se han realizado pronunciamientos tanto jurisprudenciales como legales, autores como Durango (2017) han planteado:

El objeto de la Ley 1280 de 2016 pretende: “Regular las amnistías e indultos por los delito políticos y los delito conexos con éstos, así como adoptar tratamientos penales especiales diferenciados, en especial para Agentes del Estado que hayan sido condenados, procesados o señalados de cometer conductas punibles por causa, con ocasión o en relación directa o indirecta con el conflicto armado". Se espera que con esta ley se juzgue específicamente a los responsables de grandes crímenes y se repare a las víctimas en su dimensión integral. La J.E.P. - Justicia Especial de Paz- tiene que adecuarse a los estándares internacionales; es un imperativo. (Durango, 2017, p. 29).

\section{Conclusiones}

El Estado colombiano como titular del deber internacional de protección, garantía y respeto por los derechos humanos, se ve obligado a reparar a las víctimas del conflicto armado interno. La obligación de reparar en el contexto de tránsito hacia la paz parte de varias premisas, una de ellas es que se debe tener en cuenta que por su naturaleza, las violaciones cometidas en el marco del conflicto son irreparables, de otra parte, el derecho a reparar debe ser visto como la manera en que se realizaran o lograran otros derechos y valores como la paz y la convivencia.

De otra parte, el derecho a la reparación sobrepasa el campo de la indemnización económica, encierra además el derecho a la verdad, a que se haga justicia, es decir, el derecho a la reparación incluye tanto medidas que van en aras a satisfacer la verdad, como medidas destinadas a que se haga justicia, se investigue y sancione a los responsables.

Así mismo, que los principios procesales de la justicia transicional colombiana son acordes con las exigencias internacionales, si se tiene en cuenta que para la correcta implementación de la ley que se fundamenta en la reparación integral de la víctima, ha sido necesario restringir en esta jurisdicción especial los principios procesales del derecho clásico para darle lugar a un nuevo abanico interpretativo como son los principios procesales contenido en la Ley 1448 de 2011.

\section{Referencias bibliográficas}

Alexy, R. (1993). Teoría de los Derechos Fundamentales. Madrid: Centro de Estudios Constitucionales.

Alexy, R. (2002). Derecho y razón práctica. México: Fontamara. 
Alexy, R. (2007). Teoría del Discurso y Derechos Constitucionales. México: Fontamara.

Bernal, C. (2018). La aporía de la justicia transicional y el dilema constitucional del Marco Jurídico para la Paz. En: Derechos, cambio constitucional y teoría jurídica: Bogotá Universidad Externado de Colombia.

Borowski, M. (2003). La Estructura de los Derechos Fundamentales. Bogotá: Universidad Externado de Colombia.

Calvo, N. J. (2014). Aproximaciones conceptuales al principio de progresividad y no regresividad de los derechos constitucionales. Revista Vis Iuris 1, (1). Bogotá: Universidad Sergio Arboleda.

Chiassoni, P. (2016). El discreto placer del positivismo jurídico. Bogotá: Universidad Externado de Colombia.

Congreso de la República de Colombia. (10 de julio de 2011). Ley 1448. Diario Oficial No. 48.096. Recuperado de https://www.ictj.org/sites/default/files/subsites/colombia-linea-tiempo/docs/ Ley1448/ley1448.pdf

Corte Constitucional. (30 de noviembre de 1995). Sentencia C-566. M.P. Eduardo Cifuentes Muñoz. Recuperado de https://www.corteconstitucional.gov.co/relatoria/1995/C-566-95.htm

Corte Constitucional. (8 de julio de 2009). Sentencia C-443. M.P. Humberto Antonio Sierra Porto. . Recuperado de https://www.corteconstitucional.gov.co/relatoria/2009/C-443-09.htm

Corte Constitucional. (19 de abril de 2013). Sentencia T-239. M.P. María Victoria Calle Correa. Recuperado de https://www.corteconstitucional.gov.co/relatoria/2013/T-239-13.htm

Corte Constitucional. (23 de julio de 2013). Sentencia T-469. M.P. Luis Ernesto Vargas Silva. Recuperado de https://www.corteconstitucional.gov.co/relatoria/2013/T-469-13.htm

Corte Constitucional, Sala Plena. (29 de abril del 2015). Sentencia C -284. M. P. Mauricio González Cuervo. Recuperado de https://www.corteconstitucional.gov.co/RELATORIA/2015/C-227-15. htm

Correa, M. (2017). Justicia transicional en Colombia: Balance y ... desafíos constitucionales. En: Justicia Transicional: el caso de Colombia. Bogotá: Universidad Externado de Colombia.

De Greiff, P. (2009). Una concepción normativa de la Justicia Transicional. En: Justicia y Paz: ¿Cuál es el precio que debemos pagar? Bogotá: Intermedio Editores y Fundación Seguridad y Democracia.

Díaz, C. (2010). Elementos para un programa administrativo de reparaciones colectivas. En: Tareas Pendientes: propuesta para la formulación de políticas públicas de reparación en Colombia. Bogotá: Centro Internacional para la Justicia Transicional (ICTJ).

Durango, G. (2017). Amnistía y derechos fundamentales políticos como límites contramayoritarios. 
Análisis desde la jurisprudencia de la Corte Interamericana. Bogotá: Universidad Nacional de Colombia.

Dworkin, R. (1997). ¿Es el derecho un sistema de reglas? México: UNAM e Instituto de Investigaciones Filosóficas.

Dworkin, R. (2002). Los derechos en serio. Barcelona: Ariel.

Esparza, I. (1995). El principio del proceso debido. Barcelona: J.M. Bosch.

Himma, K. E. (2011). Derecho y moral: el debate entre el positivismo incluyente y el excluyente. Bogotá: Universidad Externado.

Ovalle, J. (2011). Teoría general del proceso. México: Oxford University Press.

HumanosTreves, R. (1988). La sociología del Derecho. Orígenes, investigaciones, problemas. Barcelona: Ariel. 